\title{
A blended learning concept for an engineering course in the field of color representation and display technologies
}

Oliver Vauderwange, Peter Wozniak, Nicolas Javahiraly, Dan Curticapean

Oliver Vauderwange, Peter Wozniak, Nicolas Javahiraly, Dan Curticapean, "A blended learning concept for an engineering course in the field of color representation and display technologies," Proc. SPIE 9946, Optics Education and Outreach IV, 99460Y (27 September 2016); doi: 10.1117/12.2237612

SPIE Event: SPIE Optical Engineering + Applications, 2016, San Diego, California, United States 


\title{
A blended learning concept for an engineering course in the field of color representation and display technologies
}

\author{
Oliver Vauderwange ${ }^{*^{\mathrm{a}}}$, Peter Wozniak ${ }^{\mathrm{a}}$, Nicolas Javahiraly ${ }^{\mathrm{b}}$ Dan Curticapean $^{\mathrm{a}}$ \\ ${ }^{a}$ Offenburg University, Badstr. 24, 77652 Offenburg, Germany \\ ${ }^{\mathrm{b}}$ University of Strasbourg / ICube, Boulevard Sébasten Brant, BP 10413, F-67412, Illkirch France
}

\begin{abstract}
The Paper presents the design and development of a blended learning concept for an engineering course in the field of color representation and display technologies. A suitable learning environment is crucial for the success of the teaching scenario. A mixture of theoretical lectures and hands-on activities with practical applications and experiments, combined with the advantages of modern digital media is the main topic of the paper.

Blended learning describes the didactical change of attendance periods and online periods. The e-learning environment for the online period is designed toward an easy access and interaction. Present digital media extends the established teaching scenarios and enables the presentation of videos, animations and augmented reality (AR). Visualizations are effective tools to impart learning contents with lasting effect. The preparation and evaluation of the theoretical lectures and the hands-on activities are stimulated and affects positively the attendance periods. The tasks and experiments require the students to work independently and to develop individual solution strategies. This engages and motivates the students, deepens the knowledge.
\end{abstract}

The authors will present their experience with the implemented blended learning scenario in this field of optics and photonics. All aspects of the learning environment will be introduced.

Keywords: Education, Education in Optics and Photonics, Blended Learning, Active Learning, Hands-on Optics

\section{INTRODUCTION}

This Paper marking the end of a series of publications we presented over the last four years. The focus is on the development of an engineering course in the field of color representation and display technologies. We built up a mixture of theoretical and practical lectures, hands-on workshops and practical projects. The goal is a deeper understanding in the field of digital color representation and display technologies. The students need a broad theoretical scientific know-how, to understand the underlying ideas. Practical tests and exercises are essential. Hands-on workshops are the ideal way to combine theory and practice. With four hands-on workshops we are close to our aim to expand the practical education in scientific and production-related form even more. The last step is the development and the realization of a blended learning concept for the engineering course "Media technology: color rendering and display technologies". [1] [2] [3]

\section{E-LEARNING}

Education is always a long-term aim. In return, the success is also long-lasting. Today it is important to use modern teaching methods and digital media. Personalized methods, which are adapted to the learner's individual needs, can be used. But good learning solutions are very complex and stand always for a high investment level. The quality is always directed to the learner and his expectations. In this context quality is relative, no absolute size and only individually measurable. For the implementation of an e-learning solution the reference to the user takes a major role [4] [5]

\subsection{Theoretical background}

The actual versions of e-learning solutions with interactive media are all characterized by the growing understanding of teaching and learning processes and the advancement of learning theories. This is not only connected with the technical advancement of the devices, but also with the change in the self-image of educational institutions. Still there exist the classical forms of teaching and learning and new informal learning forms in parallel to each other. But by the availability of Web 2.0 (Blogs, Podcasts; YouTube etc.) there are a lot of possibilities to collect information what will lead to the increasing importance of the informal learning. [6]

* Corresponding author: oliver.vauderwange@hs-offenburg.de

Optics Education and Outreach IV, edited by G. Groot Gregory, Proc. of SPIE Vol. 9946, 99460Y

(C) 2016 SPIE $\cdot$ CCC code: $0277-786 X / 16 / \$ 18 \cdot$ doi: $10.1117 / 12.2237612$ 
Today in the area of e-learning a big term variety is given. "Technology-based learning", "online learning", "computeraided learning" and "multimedia learning" are only some terms which are often used synonymously to each other. Reason for this is that there still no unequivocal and universally valid names were fixed. These terms have common, that e-learning is understood as a process of learning and teaching with electronic media. One explanation which is very often used defines e-learning as an upper concept for all variations of the use of digital media for teaching and learning purposes. Digital data mediums or the internet are used to provide knowledge for the interpersonal exchange or the common work on digital artefacts. In this context the meaning of the terms interactivity and multimediality is relevant. Multimediality is defined as the simultaneous application of different forms of communication. Interactivity denotes the dimension of interaction which takes place between different subjects. One of the subjects could be a technical system. [6] [7] [8]

Digital Media enables a wide variety of technical implementations, what is the reason for the very general definition of e-learning. These can be divided into the following different technology forms. Distributive technologies are used for the transfer of information and following a more teacher oriented approach. Information and materials are made available online or are sent to the learner in digital form. In the use of interactive technologies the acquisition of knowledge and competences is in the center. The learner uses the possibility of interacting with a computer. Collaborative technologies allow the virtual learning. The aim is a team-centered learning with the help of digital media, which allows the communication between the teacher and the learner. [9]

For the conception of our blended learning solution interactive technologies are relevant. The different characteristics can be traced back on two basic methods. Computer Based Training (CBT) can be characterized as a classic form of elearning. Learning contents are processed didactically in independent computer applications. That allows autonomous learning. Different media like texts, graphics, videos, animations and simulations are united in an interactive multimedia learning application. Normally different offline media like CD, DVD ROM or USB-Stick are used as data medium. To use them offline offers advantages in the multimedia processing of the learning contents. No consideration on the bandwidth and the transfer rate must be taken. A CBT can be applied with a computer at any time and almost every place. A big disadvantage is the actuality, because the learning applications can't be updated automatically. Web Based Training (WBT) extends the functionality and the elements of the CBT by the use of online services. The transfer and storage of data over a network is allowed. New options for the interactive learning are given, especially in the communication between teacher and learner. But also the possibility to update learning contents at any time and link them with information from the internet is important. To be online is a basic requirement for WBTs. [6] [10] [11]

\subsection{Blended learning}

Blended learning describes a teaching and learning scenario which intends a didactically useful correlation of attendance periods and online periods. The goal is to make knowledge transfer and individual learning easier. The focus of the attendance periods should be the contact and exchange between teacher and learner. And in the online periods the learner has the possibility to call up and repeat knowledge and information fitted to the personal needs. Today, there is still no clear opinion how the shares of the e-learning in the blend should be. There is no defined standard. This mix varies widely between universities and teachers. It is influenced by different factors which are characterized by the teacher, the students and the learning environment. [12] [13]

From the point of view of the students the advantages of a blended learning scenario can be divided in the two categories flexibility and learning experience. Students appreciate the virtual learning parts because of they can choose the learning place and the learning time individually. The main problem is the expectation that less attendance periods also require a lower amount of work. But there are also deficits with time management and self-management. For the teachers blended learning offers the opportunity to discover new interaction forms with the students. This is experienced as productive when results appear in the learning process and students thereby argue better in the attendance period and discuss as well. [14]

Because blended learning can be broadly defined there are six typically used models to structure the term better. In these models the role of the teacher, the role of the didactical methods and the role of the time arrangements can vary. Nevertheless, it appears that new solutions are developed more and more often through combinations of these models. These illustrated basic forms can be adapted for the concrete teaching scenario and can be combined arbitrarily with each other. So the applications can be adapted in the best possible way to the respective teaching concept. In the attendance periods value should be given to good communication possibilities. The possibility to clear open questions on a personal level is very important. In this manner misunderstandings can be recognized and be fixed much faster. With the help of 
the e-learning application an efficient handling of tasks adapted to the individual knowledge level is to realize. Tasks can be repeated arbitrarily what is helpful particularly in the specific exam preparation. All participants of an e-learning course can access the identical information and knowledge platform. This clearly improves the chances for all students who visit the course without any pre-knowledge or can’t visit all lectures. [15] [16]

\begin{tabular}{|l|l|l|}
\hline $\mathbf{1}$ & $\begin{array}{l}\text { Face-to-Face-Driver } \\
\text { E-learning is decided on a case-by-case basis by the teacher } \\
\text { as a supplement to the curriculum. The e-learning contents } \\
\text { are mostly fixed components of the lectures. }\end{array}$ & $\mathbf{2}$ \\
$\begin{array}{l}\text { Rotation } \\
\text { Students move on a fixed schedule between regular lectures } \\
\text { and self-paced online learning. The regular lectures are used } \\
\text { for theoretical contents and afterwards the online platform is } \\
\text { used for exercises to deepening the knowledge. }\end{array}$ & $\begin{array}{l}\text { Online Lab } \\
\text { The online platform delivers the entire contents of the course. } \\
\text { Courses are taught entirely online, but in a brick-and-mortar } \\
\text { location and supervised by an teacher }\end{array}$ \\
$\begin{array}{l}\text { Flex } \\
\text { The e-learning provides the major portion of the curriculum. } \\
\text { Online instruction is primary. It is supplemented by on-site } \\
\text { personal support through tutoring or small group sessions. }\end{array}$ & $\begin{array}{l}\text { Self-Blend } \\
\text { The learner has the option to take online courses to enhance } \\
\text { the traditional classroom learning. Support is also only online } \\
\text { available. }\end{array}$ \\
\hline
\end{tabular}

Figure 1. The six models of blended learning [15] [16]

\section{MEDIA TECHNOLOGY AT OFFENBURG UNIVERSITY}

At Offenburg University the theoretical basics and principles of media technology are an integral part of the studies. Lectures for the module "Media Technology" are given over the first three semesters of the studies. "Media Technology 1 " in the first semester has the focus on important engineering basic knowledge. Four different courses with scientific and engineering basics are given and should be applied to easy examples. The second semester has the goal to consolidate the engineering basic knowledge. In "Media Technology 2" three courses are given. The students also have to do hands-on workshops in the media lab. The measuring of physical and electro-technical dimensions and the understanding of the accompanying principles are in the center. In the third semester the focus in "Media Technology 3" is on theories, technologies and applications. Three courses are given to specify the media-technical knowledge once again. And again the students have to go through the media lab.

\begin{tabular}{|c|c|c|c|c|c|}
\hline \multicolumn{2}{|c|}{$\begin{array}{l}\text { Media Technology } 1 \\
\text { Science and Engineering Basics }\end{array}$} & \multicolumn{2}{|c|}{$\begin{array}{l}\text { Media Technology } 2 \\
\text { Consolidation of the Basics }\end{array}$} & \multicolumn{2}{|c|}{ Media Technology 3} \\
\hline \multicolumn{2}{|c|}{ Mathematics } & \multicolumn{2}{|l|}{ Physics 2} & \multicolumn{2}{|l|}{ Physics 3} \\
\hline \multicolumn{2}{|l|}{ Physics } & \multicolumn{2}{|c|}{ Electronic Engineering 2} & \multicolumn{2}{|c|}{ Electronic Engineering 3} \\
\hline \multicolumn{2}{|c|}{ Electronic Engineering } & \multicolumn{2}{|c|}{ Digital Media 2} & \multicolumn{2}{|c|}{ Digital Media 3} \\
\hline \multicolumn{2}{|c|}{ Digital Media } & \multicolumn{2}{|l|}{ Media Lab } & \multicolumn{2}{|l|}{ Media Lab } \\
\hline \multirow{4}{*}{$\begin{array}{l}\text { Workload } \\
\text { Lectures } \\
\text { Self-study }\end{array}$} & & \multicolumn{2}{|l|}{ Workload } & \multicolumn{2}{|l|}{ Workload } \\
\hline & $90 \mathrm{~h}$ & Lectures & $75 \mathrm{~h}$ & Lectures & $75 \mathrm{~h}$ \\
\hline & $120 \mathrm{~h}$ & Self-study & $105 \mathrm{~h}$ & Self-study & $105 \mathrm{~h}$ \\
\hline & $210 \mathrm{~h}$ & & $180 \mathrm{~h}$ & & $180 \mathrm{~h}$ \\
\hline
\end{tabular}

Figure 2. Curriculum and workload of the module Media Technology 


\subsection{The course "Media Technology: color representation and display devices}

The engineering course "Media Technology: color representation and display devices" is an integral part of the second and third semester of the studies. A mixture of theoretical and practical lectures has the goal of a deeper understanding in the field of digital color representation and display technologies. To understand the underlying ideas, the students need a broad theoretical scientific know-how. Practical tests and exercises are essential to convey and deepen the important theoretical basics. The Students need a practical part to develop a better comprehension. [1] [2] [3]

For the broad field of digital color representation and display technologies the students need a broad theoretical scientific knowledge. We work with four segments to convey the necessary knowledge. "From light to the color" includes the scientific theories and knowledge of Newton, Maxwell, Hertz, Young, Brewster, Helmholtz and Hering. "Development of the color representation" starts with the CIE human observer and the color-matching functions and finishes with the CIE Lab color space and other color models. "From CIE-Lab color space to color management" contains the ICC color management, ICC profiles, gamut mapping and rendering intents. In the last segment "Color representation on display devices" an intensive discussion of different display technologies and its applications takes place. The established LCD technology and the promising OLED technology are in the center of the discussion. [1] [2] [3]

Currently we offer four workshops regarding the topics color representation and display technologies in our media lab. The students can be confronted with practical problems. By solving practical problems the students can deepen their theoretical scientific background. In the first hands-on workshop "light and color" the spectrometer JAZ from Ocean Optics is used which offers a lot of interesting possibilities. Differently colored LEDs are in the center of the measurements. For the second workshop "Colors and digital display devices" we use the Konica Minolta CRT Color Analyzer CA-100 with the software LabVIEW 5.0. With different tasks we introduce the students to the color representation on monitors and displays. In the third workshop "Color representation on digital display devices" mobile devices with different display technologies for several measurements and evaluations are used. In the workshop "LCD in the do-it-yourself" the students have to build simple LCDs themselves. [1] [2] [3]

\section{CONCEPT FOR THE BLENDED-LEARNING SCENARIO}

There was no decision for only one of the typical used six models (presented in figure 1). Our blended learning scenario is a combination of these models. They are adapted for this course and are combined to our teaching concept. The blended learning scenario is oriented on a self-determined learning of the students. There is a fixed schedule for regular lectures, the hands-on workshops and self-paced online learning. The visit of the regular lectures is optional. The online platform delivers the entire contents of the course. So the learner has the option to take these lectures online. The teacher has a supporting role, for example he can answer questions in the news forum or directly in the lecture. The hands-on workshops are a must-attend event. [15] [16]

The concept builds up on the e-learning software moodle, Version 2.9.2, used at Offenburg University. There are no hardware requirements given to the users. Moodle offers responsive designs for the most digital devices like PCs, tablets and mobiles. For the usage of moodle only an actual web browser is required. Helpfully is a PDF reader with which documents can be shown and commented and if necessary be printed. Other additional software is not required.

\subsection{Moodle}

Moodle is an internet-based open source software package for the development and realization of e-learning courses under the GNU public license. Moodle is copyrighted. But there are given a great number of different options to the user. The source code can be used, copied and extended by all users. The central condition is that license data neither are changed nor are deleted. The software code has to be provided to the moodle-community. This means, every enterprise and every educational institution is able to use moodle as e-learning solution. Moodle can be installed on any computer that can run PHP and support an SQL type database (for example MySQL) and is universally available. [17]

In figure 3 the workflow with moodle is shown. Teachers and learners access to moodle about the frontend. The teachers can provide the learning materials and tools for the learners. In the background operates the webserver with the database. The internet allows the access to external tools, documents and information. The learners access moodle about the individual web browser. No other software is necessary. There they get the exercises, tasks, tutorials, documents and information. It is possible to communicate with other course participants and discuss the tasks in the forum. This allows the learners to reorganize and structure all information individually. They can build up learning packages alone or together in groups and make them available to other course participants. [18] 


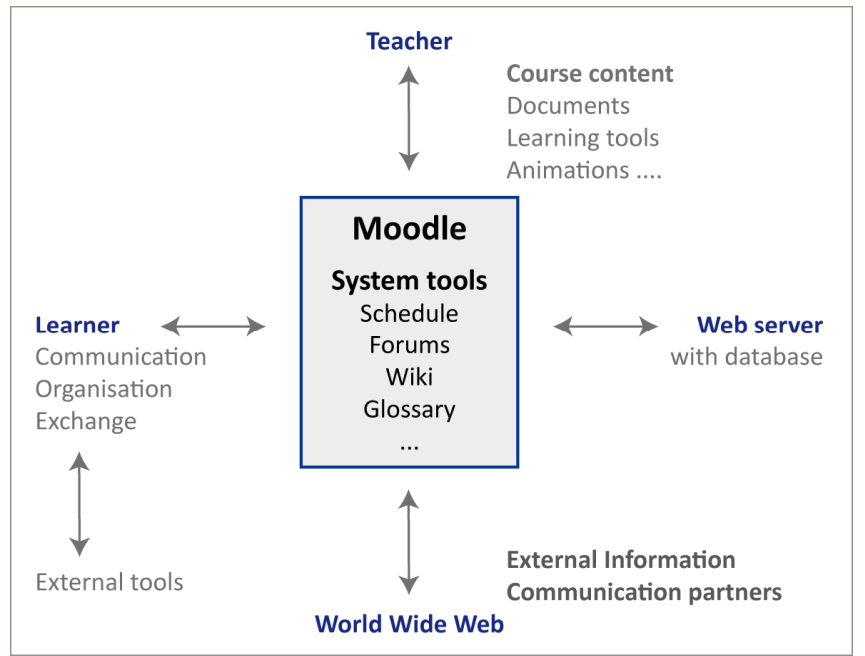

Figure 3. The workflow with moodle [18]

\subsection{Didactical style and elements}

Six e-learning components shown in figure 4 were implemented. Online communication in moodle is possible with different tools like private news or forums. The providing of content is possible by the common preparation of a wiki or glossary. Databases are used to collecting and exchanging files and information. Examinations of the learning level which are adapted to the lectures and workshops are in the center of this concept. In addition tests are developed to offer best possibilities for the self-examination to the students. Because we build a combination of lectures, workshops and elearning events, feedbacks takes place on personal level in the lectures or workshops or via the communication tools of moodle. [19] [20]

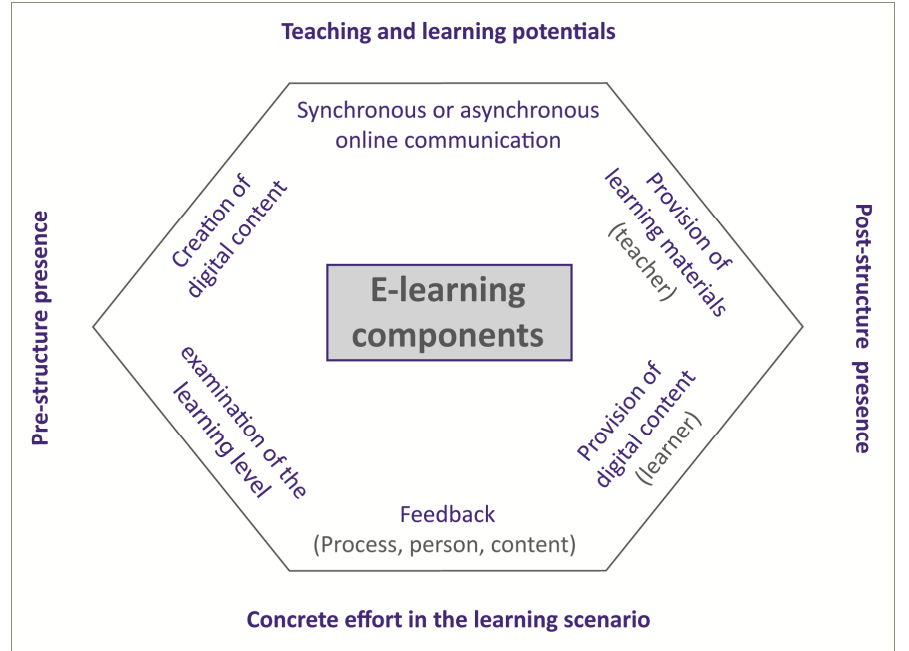

Figure 4. The integrated e-learning components [20]

Moodle provides extensive possibilities for teachers and learners. It enables the teachers to control exactly, which files at which time are made available to the learners. Also multimedia files can be embedded, edited and formatted via an editor. Efficiency controlling and motivation is possible about varied honors and feedbacks to the learners. Moreover, moodle offers automatic evaluation options for integrated tests. There are a lot of communication options for course participants and teachers like forums, wikis, glossaries, commentary function and private news. [19] [20] 


\subsection{Organisation}

The engineering course "Media Technology: color representation and digital devices" is given in four integral sections over the semesters 2 and 3. The specific theoretical basics are given in "Digital Media 2" and "Digital Media 3", the hands-on workshops are part of the media lab (see figure 2). A fixed schedule defines the attendance and online periods.

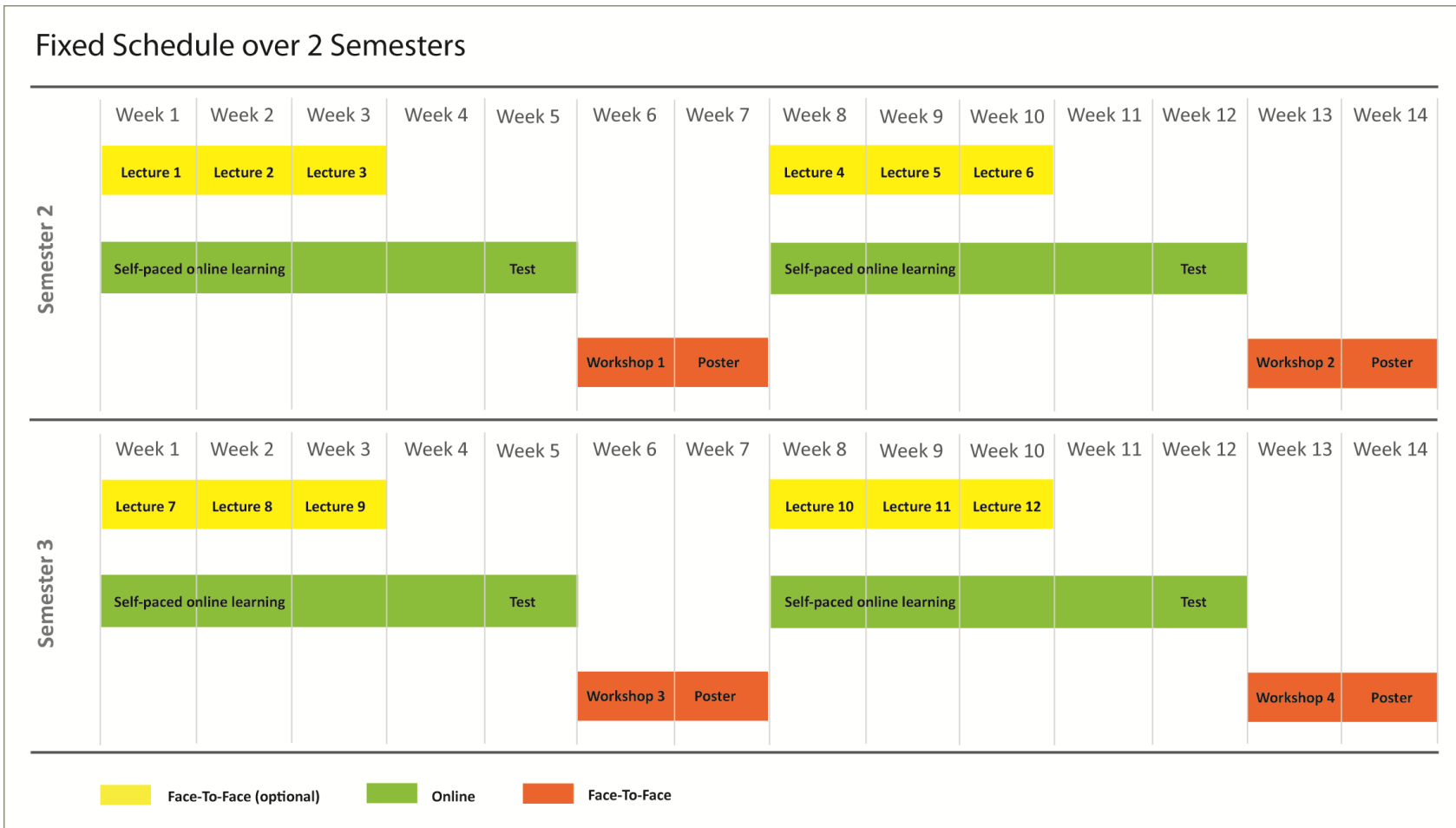

Figure 5. The schedule of the blended learning course "Media Technology: color representation and display devices"

In semester 2 the course starts with the segment "From light to color" and the hands-on workshop "Light and color". Segment 2 is called "Development of the color representation" with the hands-on Workshop "Colors and display devices". In semester 3 the title of the third segment is "From CIE Lab to color management" with the hands-on workshop "Color representation on display devices". The course finishes with segment 4 "Display technologies and display devices" and the hands-on workshop "Liquid Crystal Display in the do-it-yourself".

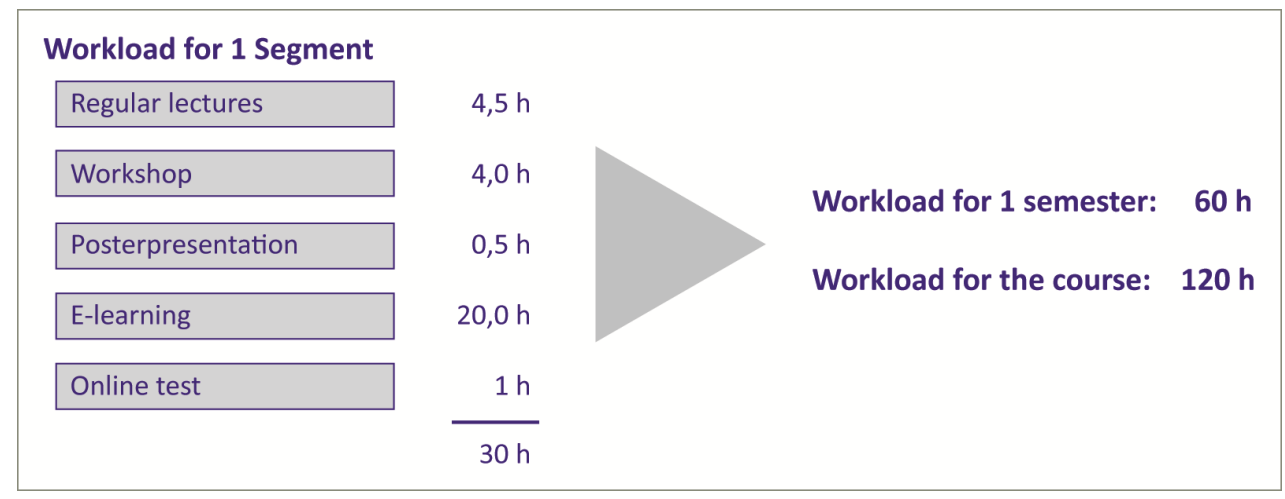

Figure 6. The planed workload of the blended learning course

The theoretical knowledge of each segment is given in three regular lectures. The attendance is optional. The online platform delivers the entire contents of the regular lectures. So it is possible for the student to work very self-paced. The teacher is in a supporting role. Support is always online available. The regular lectures can be used for a face-to-face communication. On-site personal support is also possible through in-person tutoring or small group sessions. To 
complete a segment successfully the student has to do the integrated hands-on workshop, which is a must-attend event. To be admitted to the workshop, the student has to pass an online test to examine his knowledge level. The results of the workshop must be published in a lab report and then presented to all participants with a poster.

With moodle as platform there is an easy access to the online learning materials with a lot of possibilities for interaction. E-learning is perfect to extend the established teaching scenarios with digital media. The presentation of videos, animations and augmented reality (AR) is enabled. Visualizations are effective tools to impart learning contents with lasting effect. Actually the online platform delivers the entire contents of the regular lectures in form of a lecture script. Further literature which is available in the university library is linked. Scientific papers and documents are provided. Animations, videos and podcasts to visualize contents are integrated. Content related web links for more external information be in place. But just as important are the prepared exercises, tasks and tests to examine the knowledge level of the students. In preparation for the workshops a self-produced video tutorial and a detailed technical instruction manual are available.

To deliver the learning content, we use the following so-called "learning activities" which are made available by moodle. The "learning activities" are different modules with specific duties. The operational areas and functions are shortly described in the following figure 7. [18] [19]

Chat
With the chat function it is possible to discuss online specific
topics with other course members. The chat can be read up
also after the end of the discussion.
Exercice
The students have to solve exercises and deliver the results
via moodle. The lecturer can score and comment them
immediately. The communication is directly and promptly.
Glossary
Glossaries are collections of terms with definitions for those
terms. It is a task for the students to summarize acquired
knowledge in short explanations with own words.
Test
Tests allow the students to check their own knowledge level
and are a good preparation for the examinations. The lecturer
can give feedback directly.

Figure 7. "Learning activities" provided by moodle [18] [19]

\section{PERSPECTIVE}

Augmented Reality (AR) is a special case of mediated and mixed reality concepts which has the potential of huge implications in the field of education. Today tablets and smartphones make it easy to use mobile augmented reality applications. Actually we are developing an AR learning application. It is designed as an additional learning tool and should be used in addition to existing learning books. Specific illustrations in a book could be used as markers, linking to corresponding contents in our AR app. If a Student uses the AR app he has to point his mobile device camera towards the illustration and get additional interactive content and information regarding his learning topic. The AR app content should not replace or duplicate the book but help to elaborate the contents. The app could also provide small interactive exercises. We think such an AR application is ideally suited to prepare the actual laboratory sessions and/or recap the teaching content. [21]

For the future we want to utilize augmented or virtual reality techniques for stationary laboratory exercises. Stationary setups can be extended more easily with additional interfaces. This allows more complex interactions and simulations in virtual Reality (VR) and augmented Reality (AR). At the moment we evaluate possible applications of the LEAP Motion controller for simulated experiments in VR and AR. 


\section{RESULTS}

The goal of this blended learning concept is to make knowledge transfer and individual learning easier. A first small evaluation after semester 2 showed good results. The feedback of the students was really positive. They appreciate the virtual learning parts because of the possibility to choose the learning place and learning time individually. The exercises and tasks require the students to work independently and to develop individual solution strategies. This engages and motivates the students, deepens the knowledge. Personal and career skills like communication, presentation technique and team working are developed using group tasks and hands-on workshops throughout the course. Compared to the last two years the average of the examination results is not better significantly. The well-organized and disciplined students achieved a new level and the results are impressive. But the average students don't reach the results of the last years. A problem is the expectation that less attendance periods also require a lower amount of work. Other problems are also deficits with time management and self-management. The next evaluation after semester 3 when the complete course is given for the first time to our students, will deliver more important information. Then it is possible to recognize existing problems and develop solutions to bring our blended learning course to the next level.

\section{REFERENCES}

[1] Vauderwange O., Wielage H.-H., Haiss, U., Dreßler, P., Curticapean, D., "New frontiers in color management by using modern spectrometers," Proc. SPIE 9289, $12^{\text {th }}$ Education and Training in Optics and Photonics Conference, 92891J (2014).

[2] Vauderwange, O., Dreßler, P., Wozniak, P., Curticapean, D., "Digital Devices: The big challenge in color management," Proc. SPIE 9188, Optics and Education Outreach III, 91880B (2014).

[3] Vauderwange, O., Dreßler, P., Wozniak, P., Israel, K., Curticapean, D., "Active learning in optics and photonics - Liquid Crystal Display in the do-it-yourself," Proc. SPIE 9793, Education and Training in Optics and Photonics: ETOP 2015, 97930Y (2015).

[4] Kerres, M., [Mediendidaktik: Konzeption und Entwicklung mediengestützter Lernangebote], 4. Auflage, Oldenbourg Wissenschaftsverlag GmbH, München (2013).

[5] Witte, N., "Qualität von E-Learning-Produkten - eine Beurteilungshilfe," Deutsche Gesellschaft für Personalführung e.V., January 2004, <http://www.dgfp.de/wissen/praxispapiere/e-learning-in-unternehmenkonzepte-einsatzmoeglichkeiten-qualitaetskriterien-1399> (16 July 2016 ). www.dgfp.de/wissen/praxispapiere/e-learning-in-unternehmen-konzepte-einsatzmoeglichkeitenqualitaetskriterien-1399

[6] Dittler, U., "E-Learning. Lernen, Wissen und Bildung aus dem Weg in die Postmedialität," [E-Learning. Einsatzkonzepte und Erfolgsfaktoren des Lernens mit interaktiven Medien], 3. Auflage, Oldenbourg Wissenschaftsverlag GmbH, München, 2-15 (2011).

[7] Arnold, P., [Handbuch E-Learning: Lehren und Lernen mit digitalen Medien], 2. Auflage, W. Bertelsmann Verlag GmbH, München, 15 (2011).

[8] Niegemann, H. M., [Kompendium multimediales Lernen,] Springer, Berlin, 293 (2008).

[9] Back, A., Seufert, S., Kramhöller, S., "Technology enabled Management Education: Die Lernumgebung MBE Genius im Bereich Executive Study an der Universität St. Gallen,” io Management 3, 36-42 (1998).

[10] Stoecker, D., [E-Learning - Konzepte und Drehbuch: Handbuch für Medienautoren und Projektleiter], 2. Auflage, Springer, Berlin und Heidelberg, 31 (2005).

[11]Riser, U., [Konzeption und Entwicklung interaktiver Lernprogramme: Kompendium und multimedialer Workshop Lernen interaktiv] Springer, Berlin, 59-67(2002).

[12] ***, "Blended Learning.," Leibnitz-Institut für Wissensmedien, 22 July 2015, <https://www.eteaching.org/lehrszenarien/blended_learning> (14 July 2016 ). www.e-teaching.org/lehrszenarien/blended_learning

[13] Dziuban, C.D., Moskal, P.D., Hartmann, J., "Higher education, blended learning, and the generations: Knowledge is power: No more," [Elements of quality online education: engaging communities], Sloan Consortium, Needham, MA (2005).

[14] Vaughan, N., "Perspectives on Blended Learning in Higher Education," International Journal of E-Learning, Vol. 6, 81-94 (2007). 
[15] Staker, H., Horn, M. B., "Classifying K-12 Blended Learning, " Christensen Institute, May 2012, <http://www.christenseninstitute.org/wp-content/uploads/2013/04/classifying-k-12-blended-learning.pdf> (12 July 2016). www.christenseninstitute.org/wp-content/uploads/2013/04/classifying-k-12-blended-learning.pdf

[16] Avgerinou, M.D., Gialamas, S.P. "The i2Flex Methodology: Definition, Praxis, and Conditions for Success," [Revolutionizing K-12 Blended Learning through the i2Flex Classroom Model], IGI Global, Hershey, PA, 141 (2016).

[17] ***, "Was ist Moodle," Moodle, 12 March 2014, <https://docs.moodle.org/29/de/Was_ist_Moodle> (10 July 2016). https://docs.moodle.org/29/de/Was ist_Moodle

[18] Hoeksema, K., Kuhn, M., [Unterrichten mit Moodle 2. Praktische Einführung in das E-Teaching], 2. Auflage, Open Source Press, München (2011).

[19]***, "Lernaktivitäten," Moodle Docs, 18 August 2014, <https://docs.moodle.org/29/de/Lernaktivit\%C3\%A4ten_und_Evaluationswerkzeuge > (10 July 2016). https://docs.moodle.org/29/de/Lernaktivit\%C3\%A4ten_und_Evaluationswerkzeuge

[20] ***, "E-Learning Bausteine," Landesakademie für Fortbildung und Personalentwicklung an Schulen, $<$ https://lehrerfortbildung-bw.de/elearning/orbl/bausteine/> (10 July 2016). https://lehrerfortbildung-bw.de/elearning/orbl/bausteine/

[21] Wozniak, P., Vauderwange O., Curticapean, D., Javahiraly, N., Israel, K., "Perform light and optic experiments in augmented reality," Proc. SPIE 9793, Education and Training in Optics and Photonics: ETOP $2015,97930 \mathrm{H}(2015)$ 